\title{
Transmission of Substituent Effects in the Protonation of Substituted 2-Furaldehydes in Sulfuric Acids
}

\author{
Ikchoon Lee, ${ }^{*}$ Tae Seop Uhm, ${ }^{\$}$ Zoon Ha Ryu, ${ }^{*}$ In Sun Koo, ${ }^{*}$ and Jong Pal Lee ${ }^{\delta_{*}^{*}}$ \\ Department of Chemistry, Inha linersity: Inchon 402-751. Korea \\ 'Department of Chemistry, Dongeni University: Pusan 614-714, Korea \\ ${ }^{+}$Department of Chemical Education, Gyeongsang National liniversity; Chinju 660-701, Korea \\ ${ }^{\$}$ Department of Chemistry. Dong-A Linersity; Pusan 604-714. Korea \\ Received Fehruary 21, 2002
}

Keywords : Excess acidity, Protonation. 5-Substituted-2-furaldehydes.

The transmission of substituent effects through aromatic and heteroaromatic ring has been the subject of extensive studies. ' Txperimentally, carbonyl group is one of the most commonly used and versatile probe for studying the substituent ring probe interactions. ${ }^{\text {ly.? }}$ The protonation equilibria of a number of carbonyl compounds such as aromatic acids, ${ }^{16}$ ketones ${ }^{\text {It.p... }}$ aldehydes, ${ }^{1 \mathrm{i}}$ amides ${ }^{\text {th.t }}$ and esters $^{\text {lb }}$ have been reported in concentrated solutions of mineral acid.<smiles>[R]C1=CC(=[V])C=C([R])C1=C([Y])O</smiles><smiles>[R]c1cc([R])c(C([Y])O)c([R])c1</smiles>

An interesting aspect of the results of these studies is that the resonance effect of an electron donor $\left(\sigma_{\mathrm{X}}<0\right)$ has to be regarded as a blend of normal conjugation (\#I) and $\Pi-$ polarization (\#2). The $\Pi$-polarization mechanism (\#2) has been found to apply in the hindered $\left(\mathrm{R}=\mathrm{CH}_{3}\right)$ as well as unhindered $(R=H)$ series of carbonyl compounds. ${ }^{15.3}$

In this work, the protonation equilibria of 2-furaldehydes (\#3), have been studied in aqueous sulfuric acid solution at $298 \mathrm{~K}$, eq. (1) where $7,=\mathrm{CH}_{3}, \mathrm{H}, \mathrm{Br}$ and $\mathrm{NO}_{2}$. The purpose

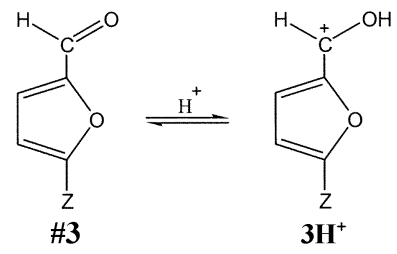

of this work is to examine whether the П-polarization mechanism also applies to the 5-memberd heteroaromatic ring systems, and if so, what causes to favor the $\Pi$ polarization (\#2) rather than direct conjugation (\#1)?

\section{Experimental Section}

Materials. The substrates, 2-furaldehydes were Aldrich special grade reagents. The water was degassed by bubbling through nitrogen gas and the sulfuric acid solution were titrated by $0.1 \mathrm{~N} \mathrm{NaOH}$ to exact concentrations.

$\mathrm{pK}_{\mathrm{BH}^{+}}$Measurements. [onization ratios, $]=\mathrm{C}_{\mathrm{BI}} \mathrm{I}^{1 / \mathrm{C}_{\mathrm{B}}}$ where $C_{\mathrm{BII}}$ and $\mathrm{C}_{\mathrm{B}}$ are molar concentrations of conjugate acid and base, were determined spectrophotometerically by eq. (2) where the absorbance D was recorded immediately

$$
\mathrm{I}-\mathrm{C}_{\mathrm{BH}^{-} / \mathrm{C}_{\mathrm{B}}}-\left(\mathrm{D}-\mathrm{D}_{\mathrm{B}}\right) /\left(\mathrm{D}_{\mathrm{BH}^{+}}-\mathrm{D}\right)
$$

after addition of the substrate into aqueous sulfuric acids of given concentration and $D_{B}$ is the absorbance of the unprotonated substrate and $D_{\mathrm{BF}}$. that of its conjugate acid. The $\mathrm{pK}_{\mathrm{B} \mid \mathrm{H}}$. values for each compound were obtained by means of the excess acidity method. ${ }^{15.31} \mathrm{eq}$. (3) where $X$ is the excess acidity (EA).

$$
\log \mathrm{l}-\log \mathrm{C}_{\mathrm{H}^{+}}-\mathrm{m} * \mathrm{X}+\mathrm{pK}_{\mathrm{BH}^{+}}
$$

The $C_{11^{\prime}}$ and $X$ values used in eq. (3) were calculated by interpolation of literature data. ${ }^{5}$ The slope, $m^{*}$, reflects primarily the susceptibility of the protonated substrate to

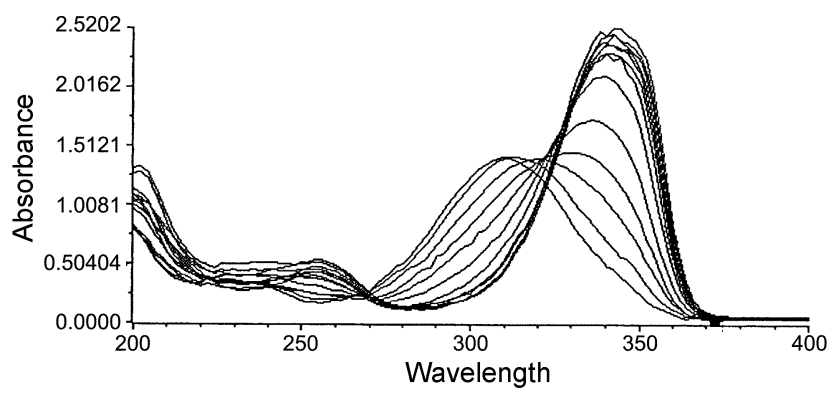

Figure 1. Absortion spectra tor protonation of 5-borme-2furakehyde in the range of $70 \mathrm{w} / \mathrm{w} \%-94 \mathrm{w} / \mathrm{w} w \%$ aqueous sulfuric acid solution. 
Table 1. Maximum absorption wayelengths for base $B$ and the corresponding protonated form $\mathrm{BH}^{-}$of 5 -substituted-2-furaldebydes (5-7.-FA)

\begin{tabular}{ccc}
\hline & \multicolumn{2}{c}{$5-\mathrm{Z}-\mathrm{FA}$} \\
\cline { 2 - 3 } & $\mathrm{B}$ & $\mathrm{BH}^{-}$ \\
\cline { 2 - 3 } & $\dot{\lambda}_{\text {mitis }}$ & $\lambda_{\text {miss }}$ \\
\hline $\mathrm{nyy}_{3}$ & 294 & 326 \\
$\mathrm{II}$ & 278 & 308 \\
$\mathrm{Br}$ & 292 & 340 \\
$\mathrm{NO}_{2}$ & 310 & 320 \\
\hline
\end{tabular}

Table 2. Values of cxecss acidity function and ionization ratio of 2lumaldelyde in $52.5 \mathrm{w} / \mathrm{w} \% \mathrm{~m}-72.0 \mathrm{w} / \mathrm{w} \%$ aqueous sulfuric acid at 25 ${ }^{\circ} \mathrm{C}$

\begin{tabular}{cccccc}
\hline $\begin{array}{c}\text { WH\% } \\
\text { acid }\end{array}$ & $\log \mathrm{CH}_{\mathrm{f}}$ & $\mathrm{X}$ & $\mathrm{D}_{308}$ & $\log \mathrm{logl} / \mathrm{C}_{1+1}$ \\
\hline 52.5 & 0.970 & 2.548 & 0.419 & -0.873 & -1.844 \\
55.0 & 0.992 & 2.763 & 0.501 & -0.741 & -1.733 \\
57.5 & 1.014 & 2.992 & 0.563 & -0.657 & -1.671 \\
60.0 & 1.033 & 3.238 & 0.689 & -0.512 & -1.545 \\
62.5 & 1.052 & 3.505 & 0.758 & -0.443 & -1.495 \\
65.0 & 1.069 & 3.795 & 0.942 & -0.279 & -1.348 \\
67.5 & 1.084 & 4.112 & 1.009 & -0.224 & -1.308 \\
70.0 & 1.097 & 4.459 & 1.364 & 0.049 & -1.048 \\
72.0 & 1.108 & 4.759 & 1.544 & 0.187 & -0.921 \\
\hline
\end{tabular}

stabilization by solvation (especially through hydrogen bonding). A typical absorption spectra in series of aqueous sulfuric acid solutions are shown in Figure 1 , and the maximum absorption wavelengths ( $\lambda_{\text {max }}$ ) used in the determination of ionization ratio, $l$, are summarized in Table 1 .

\section{Results and Discussion}

The raw data for determination of the $\mathrm{pK}_{\mathrm{B} \mid I^{\prime}}$ value by eq. (3) are shown for $Z=\mathrm{H}$ in lable 2 and the plot of logl -

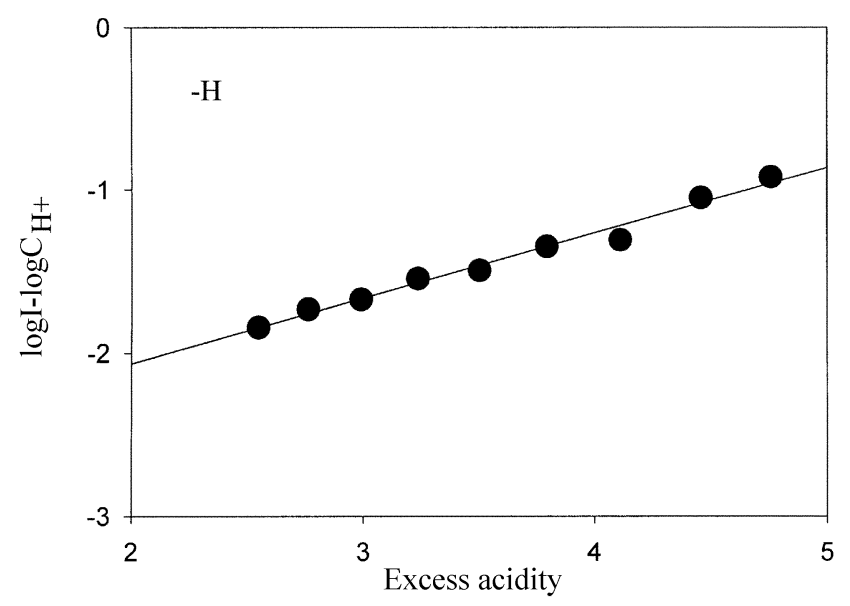

Figure 2. Plot of $\left(\log \left[-\log C_{t[1}\right)\right.$ vs. excess acidity for 2-furaldchyde in aqueous sulfuric acid at $25^{\circ} \mathrm{C}$.
Table 3. Acid dissociation constants. $\mathrm{pK}_{\mathrm{FH}-}$ and $\mathrm{m}^{*}$ values for $5-Z-$ 2-furaldchyde (5-Z-FA) in aqueous sulfuric acid at $25^{\circ} \mathrm{C}$

\begin{tabular}{|c|c|c|c|}
\hline \multirow{2}{*}{$Z$} & \multicolumn{3}{|c|}{$5-\%-\mathrm{F} \wedge$} \\
\hline & $\mathrm{pK}_{\mathrm{B} \mathrm{H}+}$ & $\mathrm{m}^{*}$ & $\Delta \mathrm{pK}_{\mathrm{BH}}$ \\
\hline $\mathrm{CH}_{3}$ & -2.50 & 0.39 & -0.37 \\
\hline $\mathrm{H}$ & -2.87 & 0.40 & 0.00 \\
\hline $\mathrm{Br}$ & -3.15 & 0.44 & 0.28 \\
\hline $\mathrm{NO}_{2}$ & -5.75 & 0.66 & 2.88 \\
\hline
\end{tabular}

$\log C_{13}$ versus $X$ is presented in Figure 2 .

All the plots exhibited good linearities and the $\mathrm{pK}_{\mathrm{BE} \mid}$ and $m^{*}$ values determined are collected in Table 3 . Reference to Table 3 reveals that the magnitude of $\mathrm{m}^{*}$ values $(0.39-0.66)$ is relatively small and are similar to those for the protonation of benzamide $(0.57)^{\mathrm{lk}}$, acetamide $(0.55)^{\mathrm{lk}}$ and benzoic acids $(0.49-0.56){ }^{11}$ These smaller $\mathrm{m}^{*}$ values are in contrast to significantly higher values for the protonation of primary anilines $\left(m^{*}=1.00\right)^{56}$ and ketones (2-acetylthiophenes, $m^{*}$ $=0.85$; phenylthiophen-2-yl methanones, $\left.\mathrm{m}^{*}=0.97\right)$. $^{\prime \prime}$ The small $m^{*}$ values are believed to provide primary evidence of strong bydrogen bonding of the protonated forms $\left(\mathrm{BH}^{-}\right)$in $\mathrm{H}_{2} \mathrm{O}$,

Our plots of the busicity $\left(\mathrm{pK}_{\mathrm{bul}}\right.$ ) against $\sigma_{p}^{+}$and $\sigma_{\mathrm{p}}$ showed negative slopes $\left(\rho^{+}=-3.12 \pm 0.57, \rho=-3.47=0.61\right)$ with slightly better correlation for the latter $(r=0.968$ and 0.971 , respectively). Although the difference in the correlation coefficients is small, the fact that the $\sigma_{p}{ }^{-}$plot did not give a better correlation indicates that through-conjugation mode (\#1) is not predominant."

There is a fairly good linearity $(r=0.971)$ in the plot of $m^{*}$ versus $\sigma_{p}$ with a positive slope $(0.30 \pm 0.05)$. This is an indication that the solvation of the $\mathrm{BH}^{+}$forms is closely related to the substituent effects. The dependence of $\mathrm{pK}_{\mathrm{BH}}$. on $m^{*}$ is given by eq. (4).

$$
\mathrm{pK}_{\mathrm{BH}^{-}}--11.63 \div 0.63 \mathrm{~m} * 1.93 \perp 0.29(\mathrm{r}-0.997)
$$

It is important that the slope (in eq. 4) is negative. This is qualitatively opposite to that commonly found." where a stronger solvation (with lower $\mathrm{m}^{*}$ values) is generally required when $\mathrm{BH}^{-}$is less stabilized by the substituent electronic effects. Thus if the mode of substituent effect transmission were the through-conjugation type (\#1), an electron donor $\left(\sigma_{p}<0\right)$ should be stabilized by the throughconjugation (\#1) and the $m^{*}$ value should be higher. ${ }^{3.4}$ The opposite trends, i.c., the smaller $\mathrm{m}^{*}$ value for an electron donor, found in the present work (lable 3) is therefore an indication that the through-conjugation mode is not operative.

We therefore conclude that the substituent effects are transmitted by the ח-polarization mode $(\# 2)$ in the protonated forms of 2-furaldehydes $\left(\mathbf{S H}^{+}\right)$based on (i) the relatively strong solvation $\mathrm{BH}^{-}$with lower $\mathrm{m}^{*}$ values, (ii) no better correlation with $\sigma_{\mathrm{p}}{ }^{-}$and (iii) the negative slope in eq. (4).

We think that strong solvation of $\mathbf{3} \mathbf{H}^{+}$with an electron 
donor $(7,=\mathrm{CH})$ is provided by the relatively low delocalizability of the oxygen atom in the hetero ring toward the carbonyl group. Theoretical analyses ${ }^{7}$ at the $\mathrm{MP} 26-31 \mathrm{G}^{*}$ level ${ }^{8}$ indicated that the through-conjugation in the $\mathbf{3} \mathbf{H}^{+}$is lower than the corresponding mode in the protonated benzaldelyyde. Thus solvation by $\mathrm{H}_{2} \mathrm{O}$ can occur at two sites, \#4, which is similar to that suggested for the hydration of benzoic acids."

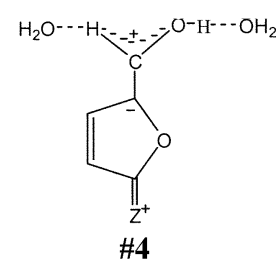

The strong solvation of the $\mathrm{BH}^{-}$forms with donor $\left(\sigma_{L} 0\right)$ is only possible in the $\Pi$-polarization mode leading to the low $m^{*}$ values and to the low possibility of the throughconjugation mode. This is supported by the similar low $\mathrm{m}^{*}$ values obtained for the protonation of hindered $(\mathrm{R}=\mathrm{CH}$ in $\# 1$ and $\# 2$ ) as well as unhindered $(R=H)$ benzoic acids $(Y=$ $\mathrm{OH}){ }^{1 \mathrm{l}}$ acetophenones $\left(\mathrm{Y}=\mathrm{CH}_{3}\right){ }^{3}$ methyl benzoates $(\mathrm{Y}=$ $\left.\mathrm{OCH}_{3}\right)^{\mathrm{lt} \text {. }}$ and benzamides $(\mathrm{Y}=\mathrm{NH}$ ) with electron donor substituents. In all of these cases. П-polarization is considered to represent the main resonance interaction mode between para-substituents and the carbonyl moiety.

Acknowledgment. This paper was supported by a basic datat research fund of the Dong-A University in 2001.

\section{References}

1. (a) Dahn. H.: Pcchy. P.: Toan. V. V. Angew Chem. Int. Ed. Engl. 1990. 29, 647, (b) Frba Dell' : Sancassan. F.: Vovi. M.: Petrillo. (3.: Vugnoli, A.: Spinelli. D.: Consiglio. (i.: Galti. P. J. Org. (hem. 1998, 53, 3564. (c) Jirba Dell'C.: Mele. A.: Novi, M.: Petrillo. (i.: Sancassant. F.: Spinelli. D. J. Chem. Soc. Ferkin Trans. 2 1990. 2055. (d) Derosa. M.: Browtl. K.: McCo. M.: Ong. K. Santord. K. J. Chem. Soc. Perkin Trans. 2 1993. 1787. (c) Noto. R.: I.amartina I.: Arone. C.: Spinelli. D. J. Chem. Soe. Perkin Trans. 2 1987. 689. (1). De.Varia P.: [Fontula, A.: Spinelli. D.:

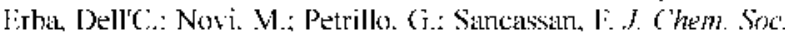
Perkin Trons. 2 1993. 649. (g) Noto. R.: Grutladauria M.: Rosselli. S.: Spinelli. D. J. Chen. Soc. Perkin Trans. 2 1996. 829. (h) Stewart. R.: Yates. K. J. Am. Chem. Soc. 1958. 80.6355. (i) Yates. K.: Stewart. R. Can. J. (Chem, 1959. 37.664, (j) Stewart. R.: Yales, K. .J. th. (hem. Soc. 1960. 82. 4059. (k) I:dward, I. T. (hang. II. S.: Yales. K.: Stewart. R. ( $\mathrm{am}$.J. (hem. 1960. 38. 1518. (1) Bromilow. J.: BrownLee. R. I. C.: Craik. D. J.: Fiske. I'. R.: Rowic. J. E.: Sadek. U. J. Chem. Soc. Perkin Trorls. 2 1981. 753.

2. Cox. R. A.: Druct. L. M.: Klausner. A. E.: Modro. T. A.: Wan. P.: Yates. K. Can. J. Chem. 1981.59.1568.

3. Chimichi S.: Istra Dell'C.: (jutladiutria. M.: Noto. R.: Novi. M.: Petrillo. (i.: Sancassan. I: Spinelli. D. J. (hem. Sot. Perkin tirths. 2 1995. 1021.

4. DeMaria. P.: Barbicri. C. L.: Spinclli. D.: Erba Dell'C.: Novi. M.: Petrillo. G.: Sancassan. F. J. Chem. Soc. Perkin Trems. 2 1991. 373.

5. Cox. R. A.: Yates. K. J. fm. Chem. Soc. 1978. 100. 3861.

6. Bagno, A.: Scorrano, (i.: More O'lerrall. R. Re'v. (hem. Internted. 1987, 7.313.

7. Lee. I.: Khee. S. K.: Kin. C. K.: Chung. D. S.: Kim. C. K. Bull. Norean Chem. Soc. $2000.2 / .882$.

8. Hehre. W. J.: Radom. L.: Schleycr. P. v. R.: Popk. J. A. tb thitio Wolecular Orbital Theon: Wiley: New York. 1986: Chapter 5. 